\title{
Telecommunications Mega-Mergers: Impact On Employee Morale And Turnover Intention
}

\author{
Keisha Chambers, PhD, Capella University, USA
}

Andrew Honeycutt, DBA, Anaheim University, USA

\begin{abstract}
The number of mergers and acquisitions grew at record rates in the United States over the past 10 years, and mega telecommunications mergers have been no exception. Three very high-profile telecommunications mergers included MCI and Verizon, Sprint and Nextel, and BellSouth and $A T \& T$. These megamergers have changed the competitive landscape dramatically in the telecom arena. Despite the popularity of mergers and acquisitions (M\&As), evidence has shown that the majority have failed to improve performance and failed to achieve anticipated strategic and financial objectives set forth in the premerger planning phase, according to J. Krug and R. Aguilera's 2004 article "Top Management Team Turnover in Mergers and Acquisitions" in Advances in Mergers and Acquisitions. The primary reason behind such common performance failures according to S. Cartwright and C. L. Cooper's 2000 HR Know-How in Mergers and Acquisitions was based on various human resources factors such as culture, management, poor motivation, and loss of talent. Based on the aforementioned post corporate merger performance failure considerations, this research study examined the impact on employee morale and turnover intention related to a recent megamerger between two telecommunications conglomerates.
\end{abstract}

\section{INTRODUCTION}

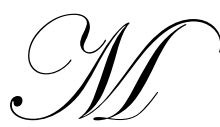

ergers and acquisitions have been essential tools of corporate growth and have become an attractive means by which to grow an enterprise. According to Cartwright and Cooper (1996), over $50 \%$ of North American business acquisitions failed as measured by an increase in shareholder value and additional studies revealed that the human capital element impacts more so than the financial factoring among the root causes of merger and acquisition failure (Cartwright \& Cooper, 1996).

As researchers narrow their focus on the issues surrounding the human capital impact on M\&A success, new information is being developed in the area of employee morale and turnover intention and the impact these factors have on employees' commitment to the new organization. Exploring how an acquisition impacts the employees of the acquired firm is contributory to an understanding of how human capital impacts the success or failure of the acquisition (Luecke, 2003). With the increased M\&A activity over the past years there have been an increasing number of studies conducted that have looked at acquired employees' reactions to a merger or acquisition through various complementary lenses.

This study established an additional lens through which the concept of employee commitment may be viewed as a pivotal component of employee morale and turnover intention. This study first explored mergers and acquisitions and briefly touched on the benefits of integration strategies. The second section defined and explored the history of the telecommunications industry. The third section investigated the impact human resources have on the success of M\&As. The third section focused on employee morale and turnover. The final section uncovered the making of the telecommunication megamerger, and revealed the organizations being researched in this analysis. The purpose of this research is to provide a theoretical framework on the impact megamergers have on employee morale and turnover intention. 


\section{MERGERS AND ACQUISITIONS}

Mergers and acquisitions (M\&As) often refer to the aspect of corporate strategy, and management dealing with the buying, selling and combining of another company. According to Banal-Estañol and Seldeslachts (2004), mergers and acquisitions are often created to expand a current organization or operation aiming for long term profitability and an increase in market power. Mergers and acquisitions have continued to experience dramatic growth (Banal-Estañol \& Seldeslachts). Record breaking megamergers have become a commonplace across the globe, in spite of the disparity of failure versus successful stories (Feldman \& Spratt, 1999).

Mergers and acquisitions, historically have failed to significantly add value to the acquiring firm (King, 2004). Despite the goals established pre-merger, such as increasing shareholder value, expanding market share, and operating more efficiently, the key element to the success of a merger or acquisition is often overlooked, that key element being, human capital. Feldman and Spratt (1999) acknowledged that key people often leave with core technology, crucial customer relationships, proprietary knowledge, vendor and industry relationships, and the loyalty of other employees who eventually follow them. These departures often disrupt business, distract the organization, induce uncertainty, and lower productivity (Feldman \& Spratt, 1999).

An acquisition is expected to create value and to provide a return on investment. It is only through the combined efforts of two sets of employees that these objectives will be achieved. However, human reactions to change are often ambivalent and difficult to anticipate. Change brings uncertainty and ambiguity. Psychological and sociological factors become intermingled and behavior influenced. The buyer's first decisions are scrutinized closely, for they give an idea of what the new working environment will be like. The merger can lead to important changes in behavior, which may help or hinder the progress of the project. According to Bruner (2005), it is already difficult to manage a group of human beings, and even more so when a merger or acquisition occurs in which two staffs with different histories, practices, and experiences are joined.

The pace of mergers and acquisitions (M\&As) picked up in the early 2000s after a short interruption in 2001. The economic slowdown and recession in the United States and elsewhere in 2001 brought a halt to the record-setting fifth merger wave. The fifth wave, beginning in 1992, seen the number of M\&As increase. According to Gaughan (2007), larger deals, some similar in size to those in the fourth wave, began to occur again. Managers were determined not to duplicate the mistakes of the 1980s therefore they focused their attention on more strategic deals that did not unduly rely on leverage (Gaughan, 2007).

During the fifth wave certain industries accounted for a disproportionate share of the total dollar volume of M\&As in the United States. In particular banking and finance industry along with the communications and broadcasting industry accounted for 26.5\% of all of U.S deals between 1993-2004 (Gaughan, 2007). However, the percentage accounted for in these industries rose from a low $7.5 \%$ in 1994 to a high of $41.9 \% 1999$. There were a combination of factors that caused these changes, including the continued impact of deregulation and consolidation of the banking industry as well as the dramatic changes that were ongoing in telecom industry and Internet-related businesses (Gaughan, 2007).

\section{Benefits Of Integration}

History shows that many mergers are cost-driven and others are built on growth expectations, they are always about change. According to Habeck et al. (2000), post-merger integration is most often the key to their success. Change in any environment is a challenge and it is important that management understands change and anticipates it along with prepare for the many aspects of change that will occur (Habeck et al., 2000).

M\&As have become a more integral part of business life. Frank (2002) acknowledges that the idea of a megadeal continues to haunts floors of the world's largest companies, as is the case here between the two telecommunication conglomerate companies being researched. Therefore for companies involved in mergers or acquisitions, in an effort to prevent the hangovers that strike the majority of M\&As, management must manage their post-merger integration more consciously and professionally. The integration phase plays the most integral part in the success or failure of the merger (Bruner, 2005). 
The heart of the post-merger stage is the integration of the strategic capabilities of the two companies in order to realize the potential synergies and to create the expected value added (Buono \& Bowditch, 1989). As a result, a certain atmosphere has to be generated that allows the transfer of resources and skills. Managers of different hierarchical levels have to interact with colleagues from the partner organization (Haspeslagh \& Jemison, 1991; Jansen, 2001; Picot, 2002). The intention is to coordinate, adapt, change, reorganize, and to set up common structures and processes in the different business areas.

According to Kusstatscher and Cooper (2005), effective communication and interaction between the merging partners is the indispensable component for the creation of an atmosphere that allows for the transfer of capabilities. Kusstatscher and Cooper (2005) reported that the transfer and integration of capabilities will only be successful under the conditions that both partners demonstrate some understanding and respect for each other's organizational structures, processes and corporate culture. In addition, the willingness to cooperate and the availability of financial and nonfinancial resources are crucial to enabling integration success (Haspeslagh \& Jemison, 1991). This explains why managerial behavior is crucial after the signing of the contract.

The incorporation of two companies on a strategic level means coordinating their strategies, their vision, the business units and their management orientations (Jansen, 2001). In addition, personnel integration has to be achieved in terms of harmonization of management styles, and incentives, personnel development, conflict management, socialization, communication and decision making structures along with processes. According to Jansen (2001), personnel integration, cultural integration is an often forgotten crucial factor in the integration of two companies. Cultural integration means solving the question of how far corporate cultures should be maintained or absorbed, according to which norms and values the merged organization should live and work, and which messages should be transmitted to the environment. In prior research, Cartwright and Cooper (1994) showed that the human factor in many integration phases is one of the most important factors in determining success or failure of a merger or an acquisition.

One of the most important factors in how well two companies integrate depends greatly on how well the integration is managed (Meschi, 1997). Fisher (1994) asserted that the most success and best mergers were those where managers of both companies took the time to thoroughly understand what they were getting into. The leaders must be willing to create a new culture that makes use of the best parts from both partners. In order to convince all company members, it is essential to be honest with employees about all aspects of agreements and to take time to reassure valuable workers that their jobs are safe. According to Meschi (1997), it is crucial that the two organizations follow an intended strategy of cultural integration and are ready to spend some time on it. Brooks and Dawes (1999) posted an optimistic perspective and argued that merging institutions may gain competitive advantage if they used the cultural integration in a positive way. By extending their horizon and by matching cultural developments to the dynamics of the environment, the merging companies can achieve significant skills which are important success factors in a competitive market (Brooks \& Dawes, 1999).

\section{HUMAN RESOURCES}

History shows that only 30-40\% of all mergers and acquisitions are successful, despite companies stating that their merger has been successful but have been unable to derive the kind of benefits that were expected, triggers the question what is stopping these companies from achieving complete success (Ajjarapu, 2004). Ajjarapu reported that one of the main reasons for failure of a merger or acquisition is based on human resources neglect. Companies which have failed to recognize the importance of human resources in their organizations and their role in the success of integration have failed to reach success. Dixon and Nelson (2005) reported that HR professionals are not included as part of the M\&A team, which is typically comprised almost entirely of people from finance, IT and other disciplines seen as essential to making the deal work.

Unsuccessful merger activity is fast becoming the norm and one of the main reasons behind this is the underestimating impact culture has on merger success. Cartwright and Cooper (2000) acknowledged that the leading roles of modern human resources functions are to be actively engaged in the organization and perform as a business partner and advisor on business-related issues. Gaughan (2005) stated: 
Human resource departments in today's organizations are practical and strategic. As such, they can add significant value for companies through development, managing personnel conflict, reinforcing the new HR system and corporate culture, and providing leadership and communication to reduce turnover. (p. 20)

This is particularly critical in the area of mergers and acquisitions.

People issues have been the most sensitive but often ignored issues in a merger and acquisition (Giles, 2000). When a decision is taken to merge or acquire, a company analyses the feasibility on the business, financial and legal fronts, but fails to recognize the importance attached to the human resources of the organizations involved. Organizations fail to realize that people have the capability to make or break the successful union of the two organizations involved. Ajjarapu (2004) reported that it is important for organizations on the verge of integration to analyze the feasibility of the integration of key players from the human resource side of the house. Research showed that only 35\% of senior HR executives were involved in M\&A activities (Giles, 2000; Liberatore, 2000). Other research reported that $80 \%$ of combinations failed at the implementation stage as a result of the following factors; an inadequate road map, senior HR professionals brought in too little, too late; senior HR professionals lacking in either/ both business/global experience; an inadequate skills base overall; and ultimately, failed organizational change (Charman, 1999; Greengard, 1999).

Anderson (1999) reported that it is imperative that human resource professionals are key in pre-merger discussions and the strategic planning phase of mergers and acquisitions early as to allow them assess to the corporate cultures of the two organizations. Being involved in the pre-merger stage allows HR to identify areas of divergence which could hinder the integration process. HR plays a vital role in addressing any communication issues, compensation policies, skill sets, and company goals that need to be assessed (Deal \& Kennedy, 1999). Deal and Kennedy (2000) reported that it is imperative to involve HR to handle other issues such as addressing employee concerns, developing a detailed integration plan for merging the people of the two organizations, conduct talent audits, manage downsizing with care and most importantly motivate employees (Deal \& Kennedy, 2000).

A study conducted by The Society for Human Resource Management revealed that more than two-thirds of the senior managers interviewed had been involved in three or more mergers, acquisitions or joint ventures within the past 5 years. Key results of the survey indicated that, while the experience level in corporate America is deep, the quality of such M\&A activities has gone missing.

The findings included:

[1.] Only $43 \%$ of respondents reported success in achieving the expected pre-deal synergies.

[2.] Of the $82 \%$ of respondent companies that listed growth in market share as the most important expected synergy of the merger, only $49 \%$ reported achieving the goal.

[3.] Companies for whom the drivers were leadership in a consolidating industry and enhanced brand strength reported similarly disappointing results.

[4.] Respondents reported that the major obstacles to M\&A success were:

[a.] Inability to sustain financial performance (64\%)

[b.] Loss of productivity (62\%)

[c.] Incompatible cultures $(56 \%)$

[d.] Loss of key talent (53\%)

[e.] Clash of management styles (53\%) (p. 5)

Dixon and Nelson (2005) stated:

These results give a clear indication and provide a basis for healing the M\&A patient or at least starting the treatment with the right prescription. After all, three of the five obstacles listed above fall squarely within the human resource arena. (p. 5)

Most of these senior HR leaders were not included in the pre-deal planning activities by their own companies. With so much to offer and a general consensus of the positive correlation between HR involvement and 
the success of mergers and acquisition, the question remains as to why HR does not play an integral role in the M\&A proceedings (Dixon \& Nelson, 2005).

\section{EMPLOYEE MORALE AND TURNOVER INTENTIONS}

As many organizations are discovering the hard way, the human resource functions are critical to the success of a merger or acquisition. In the increasingly knowledge-intensive marketplace, the acquisition of human capital is imperative and must be at the top of all organizations list of M\&A objectives (Buono \& Bowditch, 1989). In light of this, employee retention and satisfaction are key goals that demand increased focus throughout the M\&A process. A study conducted in 2000 , showed that $75 \%$ of mergers failed to deliver shareholder value, which was greater than the industry average. Another study showed that up to $70 \%$ of M\&A transactions fail to deliver value (Dixie \& Nelson, 2005).

It appears that these failure rates are nothing new. In 1995 Mercer studied $150 \$ 500 \mathrm{MM}+$ deals and found that $50 \%$ failed to meet financial objectives. Primary causes cited were inadequate due diligence, overestimation of synergies, conflicting corporate cultures, and poor/slow integration process (Risberg, 2003). In 1996 Coopers and Lybrand (as cited in Reed \& Lajoux, 1998) studied 125 acquisitions and found that 66\% failed to meet financial objectives. Primary causes cited were slow pace of integration and weak post-merger management (Reed \& Lajoux, 1998).

Many organizations focused more on the tangible products and financial goals and failed to recognize the human capital risks and opportunities were critical to achieving their M\&A objectives. Dixon and Nelson (2005) acknowledged that the human capital aspect is critical to success, and that it is the legal, finance, and human resource departments that drive strategic work and integration processes. These departments are often overlooked, which is the primary cause of why deals often go astray. The most important of the human capital considerations are employee retention and productivity. One recent study of failed acquisitions found that management attrition rates soared $47 \%$ over the 3 years following the acquisition. Employee satisfaction dropped by $14 \%$ and productivity dropped 50\%. Such statistics illustrate just how high the human capital stakes are during a merger and acquisition (Dixie \& Nelson, 2005).

According to Dixie and Nelson (2005), in any merger or acquisition, regular communication with key stakeholders, most notably employees, is critical. Far too often key decisions regarding the merger are dragged out, destroying employee morale in the process.

Low morale can gradually destroy employees' commitment, hurt the product or service offered, and alienate the clients and customers the organization serves. Bohl (1989) stated that "poor morale is contagious. It may begin with one dissatisfied employee and broaden into a general malaise, or spread from department to department and finally infect the entire organization. Insidious as it may be, poor morale is reversible" (p. 52).

Turnover occurs when employees leave the organization. The fact that human capital plays such a vital role in the outcome of an organizations financial performance, the negative impact of employee turnover gets both executives and HR professionals' ever more concerned (Deal \& Kennedy, 1999). The link between high turnover and low financial performance for corporations is strong (Huselid, 1995). When employees leave, they take with them their knowledge, skills and abilities that helped contribute to goals, profit and performance of the organization. According to Munck (2001), turnover has been shown to cause a decrease in productivity and often contributes to low employee morale. It also means that the organization will have to spend more time interviewing potential candidates, preparing offers and training new employees (Dooney, 2005).

Not only are there quantitative impacts to turnover, but the quality of personnel leaving an organization is also important. According to Abrahamson (2004), turnover represents more than a monetary loss. Often those employees who leave the organization are the most valued employees. All the money the company invested in that employee walks out the door, hence profits are literally walking out the door. In addition a new employee must start the learning process at the very bottom of the quality and productivity curve, which in turn has a direct impact on the organizations bottom line, and directly impacting customer service. 
Mergers and acquisitions represent change, and it is this change that generates different emotions among different employee groups. While employees from an acquiring company may feel excited about the new challenges that the integration brings to them, employees from an acquired company may have very different reactions, such as feeling anxious, uncertain, or even intimidated as they go through major changes (Machiraju, 2003). In the face of organizational changes from M\&As, employees tend to be worried with issues such as job security and their future careers with the organization (Daniel \& Metcalf, 2001).

According to Wasserstein (2001) when uncertainty drags on without being addressed, or when employees do not have a good understanding about the change process or new work roles and standards, it impedes productivity and performance. The rumor mill begins and employee morale not only decreases, but many employees do not wait around: they jump ship and leave the company. For example, when Hewlett Packard (HP) announced its merger with Compaq, employees became focused on securing their jobs instead of serving customers. Consequently, HP lost customers to other competitors (Nguyen \& Kleiner, 2003). Given that change is inevitable when two organizations are combined, communicating upfront about what will happen can help prepare employees for these changes.

\section{MAKING OF THE TELECOM MEGA-MERGER}

AT\&T has undergone several restructurings in its history. Before AT\&T broke up in 1984 it dominated the local and long distance telecommunications business in the United States (Majumdar, 2006). With an eye on more exciting industries, such as the computer business, AT\&T parted ways with its "boring" local operating companies. These businesses spun-off into seven regional operating companies, many of which gained much success. AT\&T shareholders received one share in each of the regional companies for every ten shares held in AT\&T (Rohde, 2000). They also still owned ten shares in the new AT\&T, which would prove to be a company that would engage in some of the more notable merger failures in merger history.

The AT\&T that emerged from the spin-off had the unenviable track record of conducting some of the worst mergers in history. AT\&T proved to be a company that had difficulty learning from its mistakes and would proceed to initiate ever larger merger blunders (Crandall, 1991). The spin-off of the operating companies allowed AT\&T to enter the computer industry as an antimonopoly consent decree had prohibited it from using revenues from its telecommunications business to finance competitive ventures into other industries (Rohde, 2000). When AT\&T failed in the computer business, it acquired NCR in a hostile acquisition and greatly overpaid after it encountered resistance from the target. Cultural rifts created further problems and AT\&T eventually broke itself up into three parts (Ross, 2002).

Recovering from its wounds received in the fourth merger wave, a new management team decided to outdo their predecessors in the merger flop business. AT\&T's management envied the growth and profitability of its progeny such as Verizon. It wished to be able to offer local phone services. Unfortunately, while it was once in this business, it had given it all away in the forth merger wave so as to be able to enter the computer business, in which it failed (Ross, 2002). The fifth merger wave version of AT\&T wanted to gain access to local phone markets and believed that two cable targets, Media One and TCI, would enable it to accomplish this. It also wanted to be a onestop shop, offering long distance, mobile, local telecommunications plus cable for its customers. AT\&T announced that it was paying approximately $\$ 100$ billion for its two cable acquisitions (Borland, 2002). After it bought the companies (rushing the sellers through without doing its own proper due diligence), it discovered that the acquired local cable lines could not support telecommunications services without a major capital infusion. Once again, AT\&T announced it was breaking itself up - again. It is ironic that after this latest M\&A debacle and breakup, AT\&T was acquired in November 2005 by one of the companies it had previously spun-off from, SBC. SBC then assumed the AT\&T name (Gaughan, 2007).

With the recent acquisition of BellSouth Corporation in a stock deal worth $\$ 85$ billion, AT\&T has created a premier global communications company committed to driving convergence, continued innovation, and competition in the communications and entertainment market (Reardon, 2007). AT\&T through the acquisition took full control of Cingular Wireless, a joint venture owned by AT\&T and BellSouth. With the merger complete, AT\&T enhances 
its U.S. leadership position in broadband, wireless services, voice services for consumers and businesses, making it the largest telecom company in North America.

\section{RESEARCH DESIGN}

This evaluated survey research to identify issues that affect morale and turnover intentions of employees of a Southeastern U.S. based telecommunications company. The study design and methodology is based on quantitative descriptive survey from which respondents ratings of study constructs are evaluated (Leedy \& Ormrod, 2005).

\section{SAMPLE/POPULATION}

The population from which survey data was solicited included unionized CWA telecommunications employees that have experienced a post-merger in the industry. There are an estimated 4,000 union employees that belong to the CWA union. Inclusion criteria required that each person solicited experienced a merger within the telecommunications industry. This method of sampling is based on probability and non-probability characteristics.

The study's participants are among members of a large multi-national telecommunications company located in the southeastern region of the United States. The surveys mailing distribution was therefore based on the aforementioned criteria with the intent of investigating the overall impact mergers and acquisitions had on employee morale and turnover intention after the recent telecommunications mega merger between two conglomerate organizations.

\section{INSTRUMENTATION}

The survey instrument used for this study is based on the Modified Edwards Morale and Turnover Intention Survey originally authored and used by Dr. Edwards in her 2001 doctoral dissertation to identify work life issues that affect morale and job satisfaction levels of midlevel administrators at a public university. Edward's survey population consisted of 634 full and part-time service professionals with a return rate of $60 \%$, a total of 381 usable questionnaires were returned. Based on the large sample population, validity and reliability constructs posited by Edwards were noted for future research considerations.

Studies suggested that intent to stay in or leave a position has been found to be a good indicator of actual turnover. Additionally, an individual's decision to leave a position may be influenced by work life variables. However, this impact has been shown to be indirect through intervening social and psychological variables such as morale and satisfaction. Edward's (2001), research reveled that when intent to leave was defined as the likelihood of leaving the position, the effect of morale was not significant (-.18). Comparatively, the effect of satisfaction on intent to leave a position was stronger and significant (-.71). This analysis suggest that the effect of work life on intent to leave was indirect, and predominantly through satisfaction. The impact on morale, while small, was significant (-.20). The effect of work life on intent to leave was indirect (-.29). Literature research reveals that morale is often viewed as related to the organization; Edward's findings support this conceptualization. The effect of work life on intent to leave the institution was mediated by morale.

This instrument has been found to be effective in evaluating ratings for career support, recognition, intradepartment relations, and working conditions as related to constructs of morale and turnover intention and this instrument will be used to survey unionized CWA telecommunications employees of a post-merger.

\section{DESIGN}

The study's participants were selected from a population of 4000 unionized CWA telecommunications employees, located in the Southeastern region of the United States, that had experienced a post-merger in the industry. There were 257 respondents to the survey representing $6.4 \%$ of the population surveyed. 
The survey consisted of 52 questions including three sections. Section one consisted of basic demographic background information about the participants. The information was collected to determine if demographic variables (age, education level, tenure in present position, tenure within the telecommunications industry, and annual income) can impact morale and turnover intentions. A six-point Likert scale was used for sections two. Section three of the survey included two ranked questions which requested a self report of the respondents overall level of morale and intent to leave which was measured on a scale of "1" indicating low morale, and not likely to leave the organization, to " 10 " indicating high level of morale and a high likelihood to leave the organization. The survey was mailed via first class postage to $4000 \mathrm{CWA}$ union employees of a major telecommunications company located in the Southeastern region of the United States. The anonymously returned survey's was mailed to the researcher for entry into SPSS. The survey instrument was estimated to take approximately fifteen minutes to complete in its entirety. Participation was strictly voluntary.

\section{RESEARCH CONCLUSIONS}

Overall the sample population of CWA telecommunications employees did not show high degrees of morale which corresponded to slightly high turnover intention. When comparing the major sections of the Modified Edwards Survey, it was noted that the section on negatively worded job related statements had the highest level of agreement (composite average 3.25) indicating that a significant improvement is needed in regard to too little job variety and too little job input particularly. It can be assumed that ambiguous job responsibilities can lead to frustration, problems with management and ultimately can effect work performance and productivity. It was also noted that the section related to career support had the lowest level of agreement (composite average 1.71) ) indicating that improvement should focus primarily on issues related to support for professional activities; fair hiring practices; fair workload distribution; and enhanced career development/promotion opportunities. The section of survey questions related to work conditions was rated the highest by the participants compared to the other survey sections (composite average 2.70) and was a positive indication of job satisfaction related to issues of resource provision; adequate parking; salary, benefits, and retirement planning.

Given the fact that all inferential statistics did not exceed the 5\% allowed to support alternative hypotheses and based on the "weak to none" classification of correlation coefficients $(0.00-0.25)$ (Berenson, Levine, \& Krehbiel, 2006), all null hypotheses for this research study were supported. Consequently, factors other than age, education, current employment tenure, total telecommunications tenure, and income were more influential on the generally low ratings of morale and slightly high ratings of turnover intention.

Since none of the demographic variables were correlated with the morale and turnover ratings, the study can conclude that the merger and acquisition itself had the greatest impact on low morale and generally high turnover intentions. What is important to note is that employees are not extremely happy with their employer or the recent union of these two massive organizations. Based on the research, being merged or acquired has a pervasive, negative impact on every aspect of how an employee views his organization.

It is assumed that this merger/acquisition undermines an employees feeling about the company and confidence in its future and will prompt employees to leave the organization. When employees are not satisfied, negative attitudes and behaviors are exhibited through difficult relationships with coworkers, low work performance, decrease in productivity and organizational commitment. Organizations need to assess and evaluate the external variables that impact morale in order to adequately address turnover. The results suggest that when morale is low, it is more likely that employees will leave the organization. Therefore examining employee's perceptions of work related issues is important to the organization in reducing turnover and retaining employees.

Mergers and acquisitions will continue to be an ever-present characteristic of the modern corporate landscape. The joining of these two organizations has created one of the largest telecommunications company in North America. Wiley stated that "mergers and acquisition activity creates vulnerability to talent loss. In order to begin the healing process, and to ensure employees remain engaged management must clearly state the tangible vision and plan of action" (Business Network, 1997). The "not knowing" side of mergers and acquisitions not only frustrate employees but also produces resentment toward the organization. 
The survey results have indicated that the merger has impacted morale in a negative way. Low morale can be assured to be caused by insecurity about their jobs, changes in processes, management, a new pay structure and most importantly the labor contract.

As the way of thinking and mindset of employees continue to increase turnover remains an issue due to problems with organizational infrastructure, downsizing, and changes in hierarchal organizational structure. This post merger study stresses the importance of involving human resources in the pre-merger integration stage, to address and manage the two diverse and distinctive cultures and management styles, in an effort to make the transition smoother.

\section{AUTHOR INFORMATION}

Dr. Andrew E. Honeycutt, Dean of the Akio Morita School of Business of Anaheim University, Anaheim, California, is the recipient of the Doctor of Business Administration degree in Marketing from Harvard University and the Masters in Business Administration degree from Boston University. He is also a Northwestern University Nissan Marketing Fellow. Andrew is also a Distinguished Fellow of Business of Shorter College, Rome, Georgia

Keisha Chambers, PhD., is a Management Consultant specializing in organizational efficiency and effectiveness.

\section{BIBLIOGRAPHY}

1. Abrahamson, E. (2004). Change without pain: How managers can overcome initiative overload, organizational chaos, and employee burnout. Boston: Harvard Business School Press.

2. Ajjarapu, N. (2004). Mergers and acquisitions: Managing the HR issues. Retrieved from http://icmr.icfai.org/casestudies/mergerissues1.htm

3. Anderson, J. E. (1999, August 9). Making operational sense of mergers and acquisitions. The Electricity Journal, 12(7), 49-59.

4. Banal-Estañol, A., \& Seldeslachts, J. (2004). Merger failures. Unpublished manuscript, University of Western Ontario (Canada) and Universitat Autonoma de Barcelona (Spain). Retrieved from http://www.ugr.es/ xxjei/JEI(39).pdf

5. Berenson, M. L., Levine, D. M., \& Krehbiel, T. C. (2006). Basic business statistics: Concepts and applications (10th ed.). Chicago: Prentice Hall.

6. Bohl, D. (1989). The effects of mergers and acquisitions. New York: American Management Association.

7. Brooks, I., \& Dawes, J. (1999). Merger as a trigger for cultural change in the retail financial services sector. The Services Industries Journal, 19(1), 194-206.

8. Bruner, R. (2005). Deals from hell: M\&A lessons that rise above the ashes. Hoboken, NJ: John Wiley.

9. Borland, J. (2002). Despite breakup, AT\&T continues to reshape telecom landscape. Retrieved from http://www.news.com/2102-1033_3-247584.html

10. Buono, A., \& Bowditch, L. (1989). The human side of mergers and acquisitions: Managing collisions between people, cultures and organizations. Washington, DC: Beard Books.

11. Cartwright, S., \& Cooper, C. L. (1994). The human effects of mergers and acquisitions. In C. L. Cooper \& D. M. Rousseau (Eds.), Trends in organizational behavior (pp. 47-62). New York: Wiley.

12. Cartwright, S., \& Cooper, C. L. (1996). Handbook of coping: Theory, research and applications. New York: John Wiley.

13. Cartwright, S., \& Cooper, C. L. (2000). HR know-how in mergers and acquisitions. London: Institute of Personnel and Development.

14. Charman, A. (1999). Global mergers and acquisitions: The human resource challenge. Alexandria, VA: Society for Human Resource Management, Institute for International Human Resources International Focus.

15. Crandall, R. W. (1991). After the breakup: U.S. telecommunications in a more competitive era. Washington, DC: Brookings Institution Press.

16. Daniel, T. A., \& Metcalf, G. S. (2001). The management of people in mergers and acquisitions. Bridgeport, CT: Quorum/Greenwood. 
17. Deal, T., \& Kennedy, A. (1999). The new corporate cultures: Revitalizing the workplace after downsizing, mergers and reengineering. Cambridge, MA: Perseus Publishing.

18. Deal, T., \& Kennedy, A. (2000). Corporate culture: The rights and rituals of corporate life. Cambridge, MA: Perseus Publishing.

19. Dixon, I., \& Nelson, N. (2005). SHRM case study: Culture management and merger acquisitions. Retrieved from http://www.shrm.org

20. Dooney, J. (2005). Communicating HR's business impact. Retrieved from http://www.shrm.org

21. Edwards, R. L. (2001). The morale and satisfaction of midlevel administrators: Differentiating the constructs and their impact on intent to leave. Doctoral dissertation, University of Hawaii at Manoa.

22. Feldman, M. L., \& Spratt, M. F. (1999). Five frogs on a log: A CEO's field guide to accelerating the transition in mergers, acquisitions, and gut-wrenching change. New York: HarperCollins.

23. Fisher, A. B. (1994). How to make a merger work. Fortune, 129(2), 66.

24. Frank, R. (2002, June 25). Where have the masters of the big mergers gone? The Wall Street Journal, p. C1.

25. Gaughan, P. (2005). Mergers: What can go wrong and how to prevent it. Hoboken, NJ: John Wiley.

26. Gaughan, P. (2007). Mergers, acquisitions, and corporate restructurings (4th ed.). Hoboken, NJ: John Wiley.

27. Giles, P. (2000, August). The importance of HR in making your merger work. Workspan, 16-20.

28. Greengard, S. (1999, October). Due diligence: The devil in the details. Workforce, 78(10), 69-74.

29. Habeck, M. M., Kroger, F., \& Tram, M. R. (2000). After the merger. London: Prentice Hall.

30. Haspeslagh, P. C., \& Jemison, D. B. (1991). Managing acquisitions: Creating value through corporate renewal. New York: Free Press.

31. Huselid, M. (1995). The impact of human resource management practices on turnover, productivity and corporate financial performance. Academy of Management Journal, 38(3), 635-672.

32. Jansen, S. A. (2001). Mergers and acquisitions (4th ed.). Wiesbaden, England: Gabler.

33. King, D. (2004). Meta-analyses of post-acquisition performance: Indications of unidentified moderators. Strategic Management Journal, 25(2), 187-200.

34. Kusstatscher, V., \& Cooper, C. L. (2005). Managing emotions in mergers and acquisitions. Northampton, MA: Edward Elgar.

35. Leedy, P. D., \& Ormrod, J. E. (2005). Practical research: Planning and design (8th ed.). Upper Saddle River, NJ: Prentice Hall.

36. Liberatore, M. D. (2000, March 2). HR's relative importance in mergers and acquisitions. Human Resource Executive, p. 48.

37. Luecke, R. (2003). Managing change and transition. Boston: Harvard Business School.

38. Machiraju, H. (2003). Mergers, acquisitions and takeovers. New Delhi, India: New Age International.

39. Meschi, P. X. (1997). Longevity and cultural differences of international joint ventures: Toward time-based cultural management. Human Relations, 50(2), 211-228.

40. Munck, B. (2001). Changing a culture of face time. Boston: Harvard Business School Publishing.

41. Nguyen, H., \& Kleiner, B. H. (2003). The effective management of mergers. Leadership and Organization Development Journal, 24(8), 447-454.

42. Picot, G. (2002). Handbook of international mergers and acquisitions: Preparation, implementation and integration. Houndmills, England: Palgrave/Macmillan.

43. Reardon, M. (2007). FCC approves AT\&T-BellSouth merger. Retrieved from http://www.news.com/FCCapproves-AT\&T-bellsouth-merger/2100-1036 3-6146369.html

44. Reed, S., \& Lajoux, A. (1998). The art of M\&A: A merger acquisition buyout guide. New York: McGraw Hill.

45. Rohde, D. (2000). AT\&T: How do you spell breakup? C-H-A-O-S. Retrieved from http://www.networkworld.com/columnists/2000/1025rohde.html

46. Risberg, A. (2003). The merger and acquisition process. Journal of International Business Studies. Retrieved from http://www.jibs.net

47. Ross, P. (2002). Regulators watching AT\&T breakup. Retrieved from http://www.news.com/2102-1033_3247612.html

48. Wasserstein, B. (2001). Big deal: Mergers and acquisitions in the digital age. New York: Warner Business Books. 